\title{
RATIONALITY OF RESIDENTIAL PLANNING BASED ON THE EFFECT ANALYSIS OF WIND ENVIRONMENT
}

\author{
HUANG, J. Z. - CAO W. W. - TAN, L. W. - YONG, X.* \\ School of Civil Engineering, Architecture, and Environment, Xihua University \\ Chengdu 610039, China \\ ${ }^{*}$ Corresponding author \\ e-mail:xiangyong@mail.xhu.edu.cn \\ (Received $8^{\text {th }}$ Mar 2019; accepted 21 ${ }^{\text {st }}$ May 2019)
}

\begin{abstract}
Among most existing residential areas, the planning designs mainly focus on the function rationality and environment beautification, but neglect the effects of residential layout on micro-climate environment. This work simulated the wind environment with different residential planning schemes using computational fluid. Then, the results of different monsoon environments were analyzed. Taking the planning scheme in Kazi Wanzhen, Urumqi as a case study, the overall rate of calm wind was higher than $50 \%$ with the calm wind in winter up to $92 \%$. It shows that the environmental effect of winter monsoon was the worst. Therefore, the original layout was optimized based on the current development strength by simulating the wind environment in this work. After optimization, the rate of calm wind in all four seasons decreased by more than $10 \%$. This result shows that the wind environment can be improved by dislocated and disclosed layout with an opening at windward side and leeward side. Therefore, the deterioration of wind environment can be relieved to improve the living environment and the overall micro-climate.
\end{abstract}

Keywords: micro-climate, computational fluid dynamics, winter monsoon, wind speed velocity, the rate of calm wind

\section{Introduction}

In recent years, people have found it important to lead the natural wind surrounding the urban area to the city when solving air pollution. The wind can be led by optimizing urban layout and constructing a natural ventilation corridor. In fact, wind field plays an important role in spreading and diluting pollutants in the air. In terms of residential areas, using wind environment is technically feasible to improve the air quality by optimizing residential planning with natural ventilation.

For a long time, residential planning has emphasized living comfort, convenience, security, beauty, energy preservation, environment protection, etc. People have not paid enough attention to the micro-climate environment up until now. The most newly-built residential areas have rational functions and complete environmental landscape and facilities with convenience. However, the irrational layouts of these areas have caused poor ventilation with air pollutants. Especially in the megacities with severe air pollution, such a problem can be more obvious. Therefore, the residential planning in urban area should focus on the effects of building layout on micro-climate environment. At present, it has become a grand new task and challenge to feasibly improve the living quality by maximizing the improvement of residential ventilation through building layout. 


\section{Materials and Methods}

\section{Research status}

There have been some research achievements about evaluating the atmospheric thermal environment with CFD at home and abroad. The studies by Oke (1973) and Summers (1965) show that the strength and location of a heat island have a certain relation with wind speed. Natural ventilation can relieve urban heat island effect and decrease air pollution (Summers, 1965; Oke, 1973; Junior et al., 2019). Dabberdt and Hoydysh (1991) made thumbnail models of street canyons in different scales for wind tunnel experiment. This study compares the distribution of wind speed field in different wind directions (Dabberdt and Hoydysh, 1991; Choudhari et al., 2018). Stathopoulos and Baskaran (1996) stimulated a wind field of a single high-level building and that of a block, respectively, for wind tunnel experiments. These studies test the simulation results (Stathopoulos and Baskaran, 1996; Rozuki et al., 2018). Yang and Li (2011) established two simple models of Hong Kong with relatively complex landforms in a small scale. The effects of thermal stratification on the thermal conditions and ventilation were studied according to thermal buoyancy and wind speed (Yang and $\mathrm{Li}$, 2011; Kumar and Jaafar, 2018). Hang et al. (2012) stimulated the pollutant distribution of 9- or 18-row high-level building array in a small scale. This study showed the effects of the height diversity on the pollutant diffusion in the air and the ventilation at pedestrian height in an ideal urban area with high-level buildings. Ouyang and Jiang (2003) found the rules of wind environment and pollutant diffusion in urban areas by data measurement (Ouyang and Jiang, 2003; Tianlei, 2019). Pontiggia et al. (2010) simulated the diffusion of hazardous gas in the city with CFD (Pontiggia et al., 2010; Omini and Akpang, 2018). In 2011, Lin and Liu studied the natural ventilation indoors and in the courtyard of traditional Yi Nationality's settlements in Yunnan by CFD simulation. It analyzes the relationship between various influence factors and the natural ventilation inside and outside of the building (Lin and Liu, 2011; Nkwuda et al., 2019). Wang (2012) studied the diffusion of air pollutant around high-level residential buildings in natural ventilation through wind tunnel test (Wang, 2012; Abija and Nwankwoala, 2018). Yuan et al. (2014) studied the diffusion of hazardous gas in the city with CFD model. In 2014, Huang studied the relationship between village form and rural settlement type in Boyang Lake Bioeconomic Zone and the natural ventilation by CFD simulation. This study further proposed the strategies about natural ventilation in the planning and design of new rural area (Huang, 2014; Sufiyan et al., 2018). With CFD, Peng (2015) stimulated and analyzed the natural ventilation effects inside of two different planes in plate-type and tower-type residential forms, which are common in Jinan. In 2016, Zhang and Jin studied the relationship between village forms and wind monsoon of the typical village clusters in the severe cold Northeast China. Strategies of optimizing the wind environment in these villages are proposed in terms of village form (Zhang and Jin, 2016).

The research status at home and abroad shows that studies on the wind environment in a region start earlier in foreign countries than in China. Such studies were mainly taken by wind tunnel experiment. With the improvement of computer hardware and simulation software, these studies are gradually taken by value simulation with wind tunnel experiment for verification. As the wind fields in different suburbs are interconnected, the overall wind field in a city should be simulated to get the correct wind fields in different suburbs. All of these studies set a foundation to this work. 
However, the existing studies with CFD simulation pay little attention to a complete residential area, especially in Western China, which becomes the subject root. Aiming at simulating the wind environment in the residential planning, this work explored the optimal mode of wind environment in a residential area for the layout optimization of residential buildings and the overall improvement of atmospheric environment.

\section{Research methods}

With the development of computer technology, digital simulations by computer can provide numerical solution to nonlinear partial differential equations. In other words, various data can be obtained by computational fluid dynamics (CFD) to save substantial experimental cost. As CFD is developing, the simulation of flow fields by computer can replace aerodynamics experiment. In the planning, it is safer and more reasonable to use aerodynamics when urban micro-climate is simulated.

CFD is realized as follows:

(1) Establishment of mathematic model (Eq.1, Eq.2). It means assigning a flow control equation, selecting a value discretization scheme, setting boundary conditions, etc. This process can be completed with commercial CFD software (i.e., ANSYS FLUENT) (Yuan et al., 2014; Wali et al., 2018). The equation (Eq.l) is the most common control equation, Navier-Stokes equation in CFD:

$$
\begin{gathered}
\frac{\partial \boldsymbol{Q}}{\partial t}+\frac{\partial \boldsymbol{F}_{i}}{\partial \boldsymbol{x}_{i}}-\frac{\partial \boldsymbol{F}_{i}^{\mathrm{v}}}{\partial \boldsymbol{x}_{i}}=0 \\
\boldsymbol{Q}=\left[\begin{array}{c}
\rho \\
\rho \boldsymbol{u}_{i} \\
\rho E
\end{array}\right], \boldsymbol{F}_{i}=\left[\begin{array}{c}
\rho \boldsymbol{u}_{i} \\
\rho \boldsymbol{u}_{i} \boldsymbol{u}_{j}+p \delta_{i j} \\
\rho \boldsymbol{u}_{i} H
\end{array}\right], \boldsymbol{F}_{i}^{\mathrm{v}}=\left[\begin{array}{c}
0 \\
\tau_{i j} \\
\boldsymbol{u}_{k} \tau_{k i}-\boldsymbol{q}_{i}
\end{array}\right]
\end{gathered}
$$

(2) Establishment of geometric model. It means drawing corresponding geometric forms in the computer according to the actual size of buildings, landforms, etc. The geometric model is simplified because the actual geographic shapes are complicated.

(3) Generation of computational grid. It means dispersing the actually continuous flow space into intermittent grid units for discrete solutions to CFD.

(4) Numerical solution to CFD. It is realized by setting the assigned turbulence model, iterative steps, residual criterion for convergence, etc. of the commercial software (Hang et al., 2012).

(5) Analysis of numerical results. After solving CFD, the results are analyzed to ensure the rationality of numerical values. Then, the actual issues are analyzed with rational numerical results to draw the wind field around buildings for modifying the irrational layout of buildings.

\section{Results and Discussion}

\section{Analysis on regional situation in the case}

Kaziwan Community in the north of Urumqi is taken as the research object due to following three reasons: 
(1) Urumqi faces a severe problem of atmospheric environment. Located in the interior of Eurasia far away from the ocean, Urumqi has temperate continental climate with dry air. According to 2015 City Rank of Haze Severity of China, Urumqi ranks at No. 76. The weather statistics show that the annual pm2.5 concentration of Urumqi is $72 \mu \mathrm{g} / \mathrm{m}^{3}$ which is much higher than $35 \mu \mathrm{g} / \mathrm{m}^{3}$ regulated in Ambient Air Quality Standards released by Ministry of Environmental Protection (Ge et al., 2016).

(2) With a long winter in Urumqi, the environmental problem caused by heating supply is obvious. According to Code for Thermal Design of Civil Building (GB50176), Urumqi is in a severe cold area. The period with monthly lowest temperature $\leq-10^{\circ} \mathrm{C}$ or daily lowest temperature $\leq 5^{\circ} \mathrm{C}$ is longer than 145 days. Due to the cold weather, the heating supply period is from October to April the next year in Urumqi. The heating period here is longer than other areas, while the fire coal for heating may cause atmospheric pollution and jeopardize the public health.

(3) Enterprises with heavy pollution are concentrated in Kaziwan. There are two cement plants (Xingong Cement Plant and Qingsong Cement Plant) within 1 mile from Kaziwan Community. A large amount of dust, sulfur dioxide, nitric oxide and other pollutants may be generated when producing cement to cause severe environmental pollution and harm the health of residents nearby. Although the government has shut down the enterprises causing heavy pollution, the environment pollution in big cities are still unsolved. The current status of pollution is especially severe in winter due to the fire coal for heating. Reducing pollution sources is an important measure, but selfattenuation of air pollutants is more positive by maximizing the ventilation.

\section{Case overview}

Located in Midong District in northeast of the city center of Urumqi, Kaziwan Community covers $55,000 \mathrm{~m}^{2}$ of land use with a volume fraction index of 3.2 and architectural density of $30.14 \%$. The overall floorage is $190,000 \mathrm{~m}^{2}$ (including the above ground floor area of 176,000 $\mathrm{m}^{2}$ and underground floor area of 14,000 $\mathrm{m}^{2}$ ).

The overall residential buildings are high level with enclosed building layout. Roads are laid surrounding the community, where pedestrian are separated from traffic. In the southwestern corner, two dotted apartments are built. Greening is concentrated in the center of community, while the greenery landscape distributes in trapezoid. Leisure footpath, hard pavage, featured landscape, green trees, etc. are composed of a rich and lifeful common activity area which provides a pleasant outdoor shared area to residents. The planning scheme creates a modern residential area with healthy biology, beautiful environment and reasonable function layout by integrating the site culture and natural conditions.

\section{Model construction and parameter analysis}

Kaziwan Community uses the traditional model of residential layout in northern China which is a typical enclosed layout. This model is a spatial layout with strong closure made of surrounding roads (Fig. 1a). For the convenience of model construction, effects of plants were neglected in this work by simplifying the whole community as a solid model composed of buildings. With this model, relatively correct simulation results can be obtained by appropriate parameter adjustment. Moreover, this model has advantages of convenient construction, rapid calculation and good convergence. 
A computational grid of Kaziwan Community (Fig. 1b) is established with ICEM software with about 1.2 million grids. This calculated quantity can ensure accuracy and realize the optimal calculation process (Nikolopoulou and Lykoudis, 2006).

In this case, the incoming flow direction of wind speed is the speed income when the boundary conditions are set within the computational scope. Based on the meteorological data of Urumqi in recent 50 years, the annual average wind speed in Urumqi is $2.47 \mathrm{~ms}^{-1}$ from 1961 to 2003 . The wind speed in summer is the fastest, followed by that in spring, autumn and winter in order. The average wind speeds are $3.08 \mathrm{~ms}^{-1}, 2.94 \mathrm{~ms}^{-1}, 2.31 \mathrm{~ms}^{-1}$ and $1.52 \mathrm{~ms}^{-1}$, respectively, in four seasons. The wind in spring is southeaster and summer and that in autumn and winter is northwester (Le et al., 2017; Fu et al., 2018). The export downstream is the pressure export and the boundary condition on ground is the wall space. The boundary conditions in other parts are symmetrically set. To avoid the result error, the parameters should be further rectified (Jing, 2018).

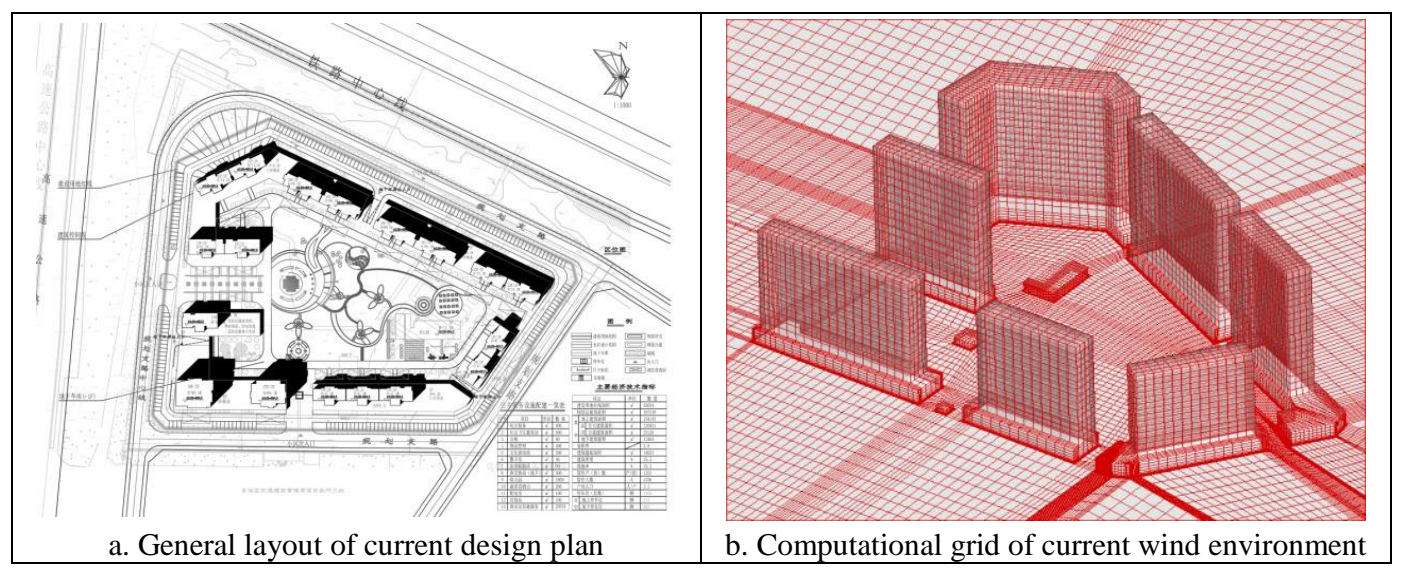

Figure 1. Overall appraisal for the current plan of Kaziwan Community and computational grid of wind environment

\section{Analysis and optimization of research results in the empirical case}

The theoretical research shows that the height of $1.5 \mathrm{~m}$ is the most obvious thermal inductance for human. The wind speed simulated for this height can intuitively display the comfort and safety in such an environment. Therefore, the wind speed field in the height of pedestrians is simulated by computational fluid mechanics in four seasons. The figures show the simulation results (Fig. $2 a-d$ ). Meanwhile, the air pollutant cannot disperse to form a calm zone when the calm rate is lower than $1.04 \mathrm{~m} / \mathrm{s}$ under $1.5 \mathrm{~m}$ as the evaluation criterion. The calm rate is the ratio between this area and the total site area. The higher calm rate means the worse effect of wind environment.

\section{Result analysis of wind speed field in the current plan}

The computational results of different monsoon fields in this plan (Table 1) show that the calm rates in four seasons are 56.25, 55.32, 55.96 and $91.82 \%$, respectively. The higher the calm rate is, the worse the wind environment will be. Therefore, the monsoon environment in winter is the worst in this case, while that in other three seasons is average. However, the calm rate in all the seasons has been over $50 \%$. Thus, it is urgent to improve the ventilation effect, especially in winter. 
According to the distribution of wind speed shown (Table 1), the maximum wind speed in winter is $1.17 \mathrm{~m} / \mathrm{s}, 3.17 \mathrm{~m} / \mathrm{s}$ in spring, $3.27 \mathrm{~m} / \mathrm{s}$ in summer and $2.71 \mathrm{~m} / \mathrm{s}$ in autumn. The area with quick wind speed in spring and summer is in three openings in the south and southeast of the area. Moreover, there are also two obvious air channels in the community in autumn. Only in winter, there is no obvious air channel due to the weak wind environment. This is because there is an opening among the buildings towards the wind direction with the maximum wind speed of $3.27 \mathrm{~m} / \mathrm{s}$ which is lower than the safety threshold of $5 \mathrm{~m} / \mathrm{s}$. It is believed that the wind environment formed in this plan is much lower than the standard of windburn. Therefore, this plan with small effects on outdoor activities can satisfy various activities at this site in terms of security (Sheng et al., 2018). Massive annex buildings cause the closure of community environment to the great extent; however, these buildings form a local calm area that is disadvantageous to pollutant dispersion.

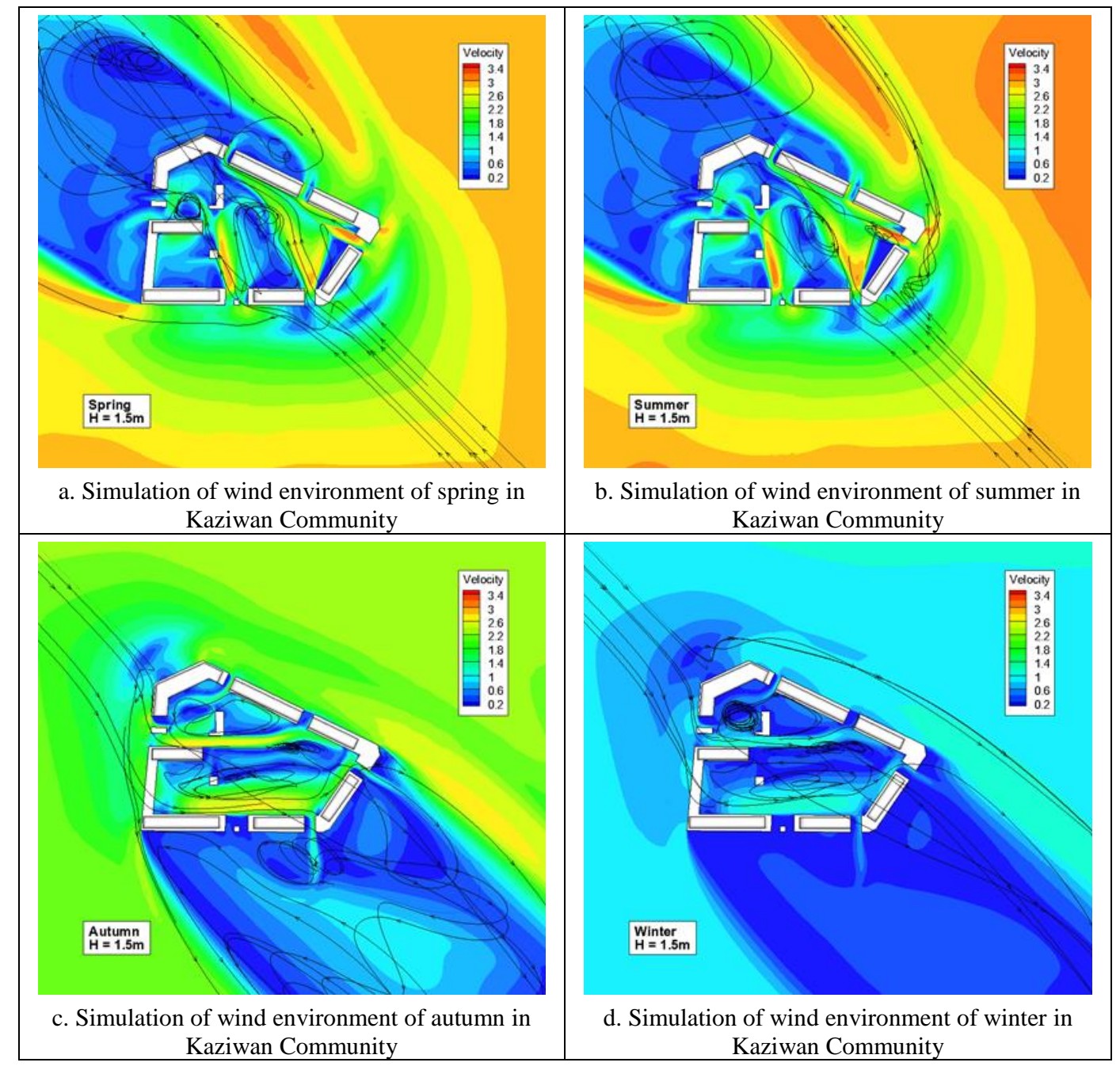

Figure 2. Simulation of current plan of four monsoons in Kaziwan Community

The areas with fast wind speed in winter are in the western entrance and the scenery greenbelt in the south. The maximum wind speed is $1.17 \mathrm{~m} / \mathrm{s}$, lower than the speed threshold of $5 \mathrm{~m} / \mathrm{s}$. Therefore, this plan with small effects on outdoor activities can 
satisfy various activities at this site. It is because the building layout at the northeast corner is vertical to the leading wind direction in winter. The enclosed layout in the north can shield the leading wind in winter. However, such a shield forms a large area of calm wind among the massive enclosed buildings in the north, making pollution more severe (Shan and Lai, 2018).

Table 1. Simulation results of wind environment in Kaziwan Community

\begin{tabular}{c|c|c|c|c}
\hline Current plan & Spring & Summer & Autumn & Winter \\
\hline Calm rate & $56.25 \%$ & $55.32 \%$ & $55.96 \%$ & $91.82 \%$ \\
Maximum wind speed & 3.17 & 3.27 & 2.71 & 1.17 \\
Minimum wind speed & 0 & 0.01 & 0.00 & 0.00 \\
Building density & 0.143 & 30.14 & 30.14 & 30.14 \\
\hline
\end{tabular}

\section{Results analysis on the wind speed fields of four seasons in the optimized plan}

The current plan does not cause the windburn but forms an area with severe calm wind, especially in winter. Therefore, adjustment is necessary for this layout to improve the calm wind area in the community during winter to the greatest extent. In this way, the pollutant gathering in the air during winter can be effectively released.

Now, the original plan is optimized with the volume rate and building height constant. The layout is optimized from the traditional enclosure to the dislocated enclosure. In other words, the overall building layout is still enclosed, while the partial layout will be adjusted to plate-type dislocated layout (Fig. 3a) to leave a corridor for ventilation for the improvement of wind environment.

With the computational grid established with ICEM (Fig. 3b), the computational quantity, $100 \mathrm{~W}$, is the same as the previous plan. The same parameters are set for calculation and simulation.

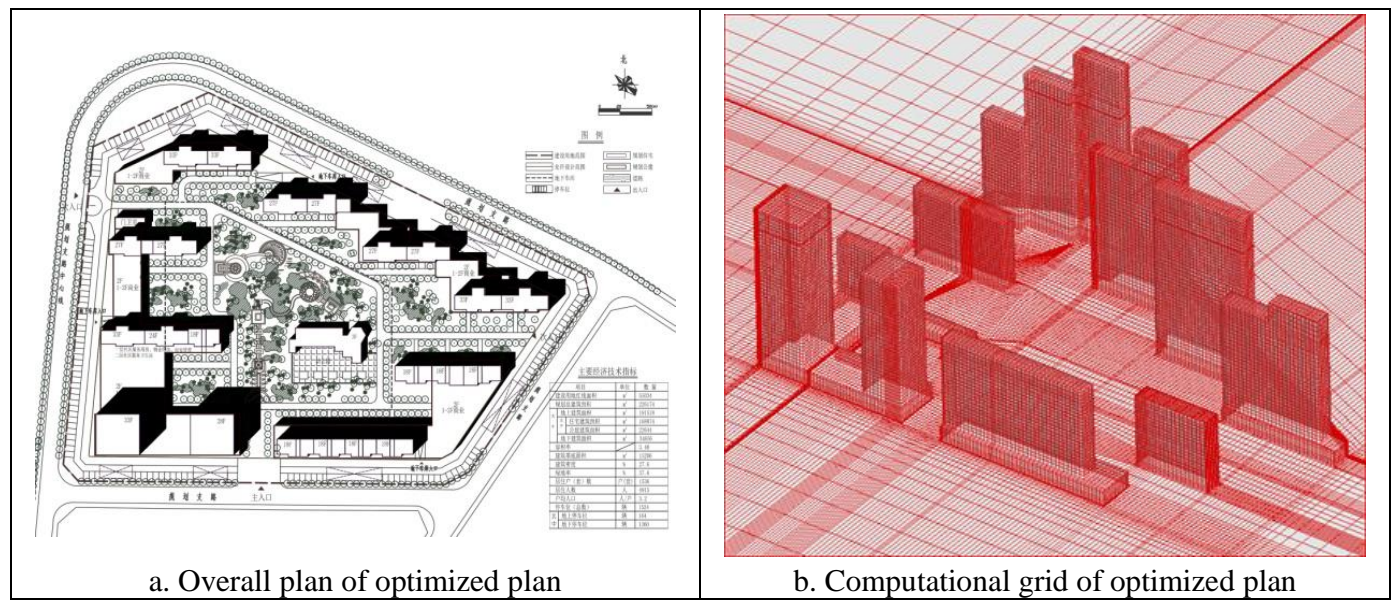

Figure 3. Overall evaluation of the optimized plan and the computational grid of wind environment in Kaziwan Community

For different monsoon speed fields, the optimized plan is simulated in the height of pedestrians in four seasons by computational fluid dynamics. The simulation results are as follows (Fig. 4a-d and Table 2). 
The figure and the table show that the calm rate in the optimized plan is $40.05,33.02$, 36.35 and $87.27 \%$ in spring, summer, autumn and winter, respectively (Fig. 5, Table 2). In terms of the environmental effect, the calm rate in winter is still the highest, while that in other three seasons shows small difference. Compared with the current plan, the optimized plan solves the problem of high calm rate. In the optimized plan, the calm rate in every season decreases by about $10 \%$. It shows that the adjustment of building layout will change the wind environment inside of a community to decrease calm rate and improve air quality.

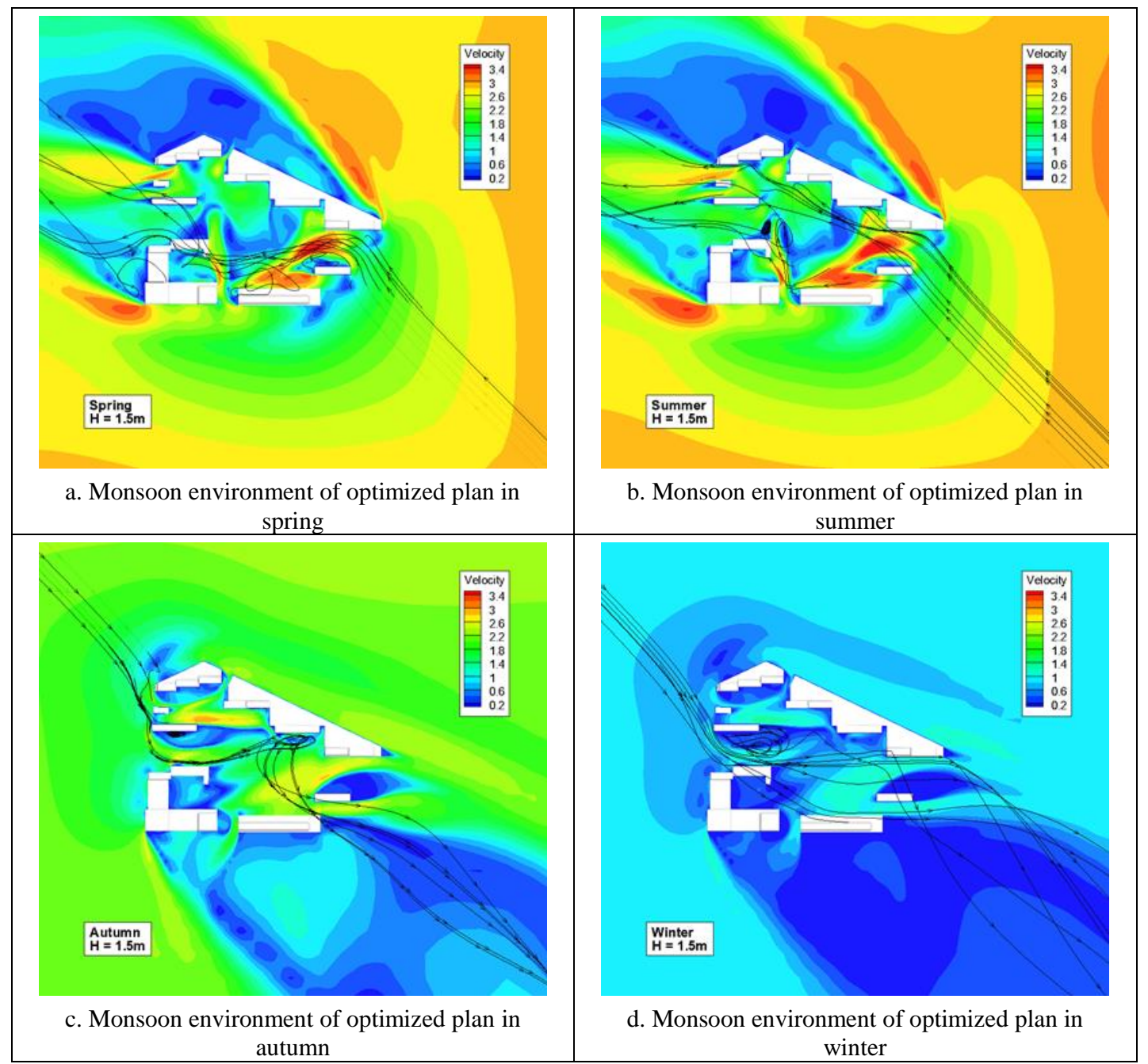

Figure 4. Simulation of monsoon environment in the optimized plan of Kaziwan Community in four seasons

Table 2. Simulation results of monsoon environment in the optimized plan

\begin{tabular}{c|c|c|c|c}
\hline Optimized plan & Spring & Summer & Autumn & Winter \\
\hline Calm rate & 40.05 & 33.02 & 36.35 & 87.27 \\
Maximum speed & 3.54 & 3.66 & 2.89 & 1.27 \\
Minimum speed & 0 & 0.00 & 0.00 & 0.00 \\
Building density & 31.81 & 31.81 & 31.81 & 31.81 \\
\hline
\end{tabular}




\section{Comparative analysis on the building layout improvement}

This work studied the comfort and safety of pedestrians. As the current plan and the optimized plan in this work are the most typical layouts in community design, this research is more persuasive for the future simulation of computational microenvironment with the universal CFD. By comparing the calculation of these two plans, following characteristics can be obtained:

(1) Layout difference between plans

Above computational results show that the changes to current layout significantly decrease the calm rate. It means that the layout has significant effect on wind environment. There are following similarities and differences between the optimized plan and current plan. First, the development strength is almost the same with the volume rate and building height constant. Second, the layout is different. In the optimized plan, the layout changes from the traditional enclosure to dislocated enclosure. In other words, the overall layout is still enclosed with the adjustment of plate-type dislocated layout in partial. This optimized layout leaves a corridor for ventilation for the improvement of wind environment.

(2) Comparative analysis on results

Simulation results show that the wind speed is fast in spring and summer when southeaster prevails. In terms of overall environmental effect, this plan has a large effect on the wind speed field of the whole environment due to the closure. In this plan, a series of calm areas form surrounding high-level buildings, which is disadvantageous to the overall ventilation in the environment. By optimizing this plan, an open corridor forms, making the overall effect of wind environment in the community constant with the external environment. This is advantageous to the ventilation in the community. In terms of internal micro-environment of the community, the wind speed is low in the current plan with only three tiny air flues in incoherency. It is difficult to fluid air exchange with the outside world. After optimization, the overall wind speed in the internal environment is slightly higher with a complete ventilated corridor.

The wind speed in autumn and winter is low when northwester prevails. The difference between internal and external wind speed is significant in the current plan, while the difference is small in the optimized plan. However, the small pattern of internal wind speed field shows that two air flues with high wind speed form near the residential area in the current plan. These flues will make pedestrians uncomfortable in autumn and winter. The optimized plan forms an open air flue in the middle but effectively resist the cold wind due to some random shelter and small enclosure near buildings. Therefore, the optimized plan makes pedestrians more comfortable.

Relation of the internal ventilation with the community and development strength is not strong, while that with the layout pattern is obvious. Dislocated enclosure can more effectively enhance the ventilation effect in the community to improve the overall air quality than surrounding enclosure (Zhang et al., 2018).

\section{Conclusions}

By simulating the wind environment in Kaziwan Community of Urumqi and its optimization analysis, following advises are obtained for the reference of creating a comfortable residential environment. First, the problem of severe wind environment due to development strength can be solved by proper layout optimization. Second, the dislocated enclosure can ensure a certain enclosure for heating and leave a ventilation 
corridor for the improvement of wind environment (David, 2017). Third, a certain ventilation opening can be left in the building layout at windward side, making the wind enter the community. This opening can optimize the wind environment in the residential area to some extent. Forth, a ventilation opening can be added in partial building layout at leeside to reduce the building separation in the direction of air flue. Therefore, the air flue is continuous in the community for a good circulating wind environment ( $\mathrm{Lu}$ et al., 2019).

In this work, the wind environment was analyzed with the optimization strategies discussed. The results showed that the planning design of residential area should consider various aspects. Except for the urban esthetics, economic benefits, sunshine spacing and other factors, the wind environment should be optimized to improve the living environment. After optimizing wind environment, the pollutant concentration decreases, and the haze pollution is relieved by accelerating air circulation. Moreover, the green energy preservation can be realized to make a positive effect on human health to some extent (Qi, 2018).

Urban planning is a discipline crossing several disciplines. The impact factors of wind environment cannot be neglected, but more factors should be considered in the actual design. Therefore, the design should be optimized by the analysis technology of wind environment in the basic design principle ( $\mathrm{Li}, 2018$ ). However, as a specific case is taken as background, the conclusion about the layout mode based on the analysis on wind environment effect is only suitable for the case. The university requires further rectification by experiment for different regions.

Acknowledgements. This research was supported by the "Systematic study of prefabricated buildings" grant of Sichuan Provincial Department of Education (NO17ZA0371), supported by "Research on the Collaborative Innovation mechanism of urban government in the new urbanization process" grant of Sichuan science and techonology department, No.2018ZR0146, Postgraduate innovation fund of Xihua University: "Research on the Collaborative Innovation mechanism of urban government in the new urbanization process" (ycjj2018060), "Study on the carrying capacity of urban infrastructure in the construction of new type of urbanization" grant of Ministry of Housing and Urban-Rural Development of the People's Republic of China (NO2016-R2-040).

\section{REFERENCES}

[1] Abija, F. A., Nwankwoala, H. O. (2018): Characterization Of Aquifers In Parts Of Abia State Southeastern Nigeria. - Earth Sciences Pakistan 2(1): 18-22.

[2] Choudhari, P. P., Nigam, G. K., Singh, S. K., Thakur, S. (2018): Morphometric based prioritization of watershed for groundwater potential of Mula river basin, Maharashtra, India. - Geology, Ecology, and Landscapes 2(4): 256-267.

[3] Dabberdt, W. F., Hoydysh, W. G. (1991): Street canyon dispersion: sensitivity to block shape and entrainment. - Atmospheric Environment. Part A. General Topics 25(7): 11431153.

[4] David, R. C. (2017): 6. Traditional Political Historiography in the Work of Laureano Villanueva. - Argos 34(66).

[5] Fu, H., Li, Z., Liu, Z., Wang, Z. (2018): Research on Big Data Digging of Hot Topics about Recycled Water Use on Micro-Blog Based on Particle Swarm Optimization. Sustainability 10(7): 2488.

[6] Ge, Q., Zheng, J., Hao, Z., Liu, Y., Li, M. (2016): Recent advances on reconstruction of climate and extreme events in China for the past 2000 years. - Journal of Geographical Sciences 26(7): 827-854. 
[7] Hang, J., Li, Y. G., Sandberg, M., Buccolieri, R., Di Sabatino, S. (2012): The influence of building height variability on pollutant dispersion and pedestrian ventilation in idealized high-rise urban areas. - Build Environment 56: 346-360.

[8] Huang, C. (2014): A study on the natural ventilation of rural residential area in Boyang Lake biologic economic zone. - Nanchang: East China Jiaotong University.

[9] Jing, G. (2018): Application of Traditional Cultural Elements in Modern Urban Public Art Landscape Design. - Argos 35(71).

[10] Junior, J. J. M., Silva, E. A., Reis, A. L. D. A., Santos, J. P. M. S. (2019): Dynamical spatial modeling to simulate the forest scenario in Brazilian dry forest landscapes. Geology, Ecology, and Landscapes 3(1): 46-52.

[11] Kumar, M., Jaafar, J. (2018): Preparation and Characterization Of Tio2 Nanofiber Coated Pvdf Membrane For Softdrink Wastewater Treatment. - Environment \& Ecosystem Science 2(2): 35-38.

[12] Le, K., Yao, J. Z., Li, Z., Ke, Z. (2017): Preparation, characterization and photocatalytic activity of novel $\mathrm{CeO} 2$ loaded porous alkali-activated steel slag-based binding material. International Journal of Hydrogen Energy 42(27): 17341-17349.

[13] Li, J. (2018): 2. Income Distribution of Garbage Disposal PPP Project Based on Modified Shapley Value Method. - Argos 35(68).

[14] Lin, C., Liu, J. (2011): A Study on Wind Environment of New-type Traditional Residential Area-Taking Residential Building of Yi Nationality in Yunnan as An Example. - Building Science 27(12): 25-30.

[15] Lu, D., Feng, L., Jie, P. (2019): Solar Cells Various Appearance Defects Automatic Simultaneous Detection System of the Greenhouses. - Acta Microscopica 28(1).

[16] Nikolopoulou, M., Lykoudis, S. (2006): Thermal comfort in outdoor urban spaces: analysis across different European countries. - Building and environment 41(11): 14551470 .

[17] Nkwuda, N. G., Theophine, M. A., Okogwu, O. I. (2019): Impacts Of Rock Mineralization And Poor Sanitary System On Borehole Waters Quality And The Health Implications. - Earth Sciences Pakistan 3(1): 10-13.

[18] Oke, T. R. (1973): City size and the urban heat island. - Atmospheric Environment 7(8): 769-779.

[19] Omini, E. O., Akpang, O. M. (2018): Cavity Detection Under Re-Enforced Concrete Floor Using Ground Penetration Radar. - Engineering Heritage Journal 2(2): 11-18.

[20] Ouyang, Y., Jiang, W. M. (2003): A Study on Environment Flow Fields in Urban Communities and Wind Tunnel Test for Pollutant Dispersion. - Journal of Nanjing University (Natural Science) (6).

[21] Peng, Y. L. (2015): A strategic study on the optimized design of natural ventilation for high-level buildings in Jinan with CFD simulation. - Shandong University of Architecture and Engineering.

[22] Pontiggia, M., Derudi, M., Alba, M., Scaioni, M., Rota, R. (2010): Hazardous gas releases in urban areas: assessment of consequences through CFD modelling. - Journal of hazardous materials 176(1-3): 589-596.

[23] Qi, X. (2018): 1. Arbitration Mechanism for Intellectual Property Disputes in Free Trade Zone. - Argos 35(68).

[24] Rozuki, N. F. A., Tajuddin, M. H., Yusof, N. (2018): Effect Of Different Solvent On Asymmetric Polysulfone (Psf) Membranes For Co2/Ch4 Separation. - Environment \& Ecosystem Science 2(2): 11-14.

[25] Shan, P. F., Lai, X. P. (2018): Numerical Simulation of the Fluid-Solid Coupling Process During the Failure of a Fractured Coal-Rock Mass Based on the Regional Geostress. Transport in Porous Media 124(3): 1061-1079.

[26] Sheng, J., Su, J., La, P., Ren, J., Ma, J., Shi, Y., Song, Y. (2018): Progress of In-Situ Study on Mechanical Properties for Micro/Nano-Structured Alloy. - Journal of Nanoelectronics and Optoelectronics 13(5): 637-645. 
[27] Stathopoulos, T., Baskaran, B. A. (1996): Computer simulation of wind environmental conditions around buildings. - Engineering structures 18(11): 876-885.

[28] Sufiyan, I., Zakariya, R., Yacoob, R., Idris, M. S., Idris, N. M. (2018): SWAT Subbasins Parameters and Flood Risk Simulations Using 3d In Terengganu Watershed. - Earth Sciences Malaysia 2(2): 10-15.

[29] Summers, P. W. (1965): An urban heat island model-its role in air pollution problems with application to Montreal. - First Canadian Conference on Micrometeorology, Toronto 22.

[30] Tianlei, W. (2019): Nonlinear Control Strategies And Planning For Underactuated Overhead Cranes. - Engineering Heritage Journal 3(1): 09-12.

[31] Wali, E., Phil-Eze, P. O., Nwankwoala, H. O. (2018): Saltwater - Freshwater Wetland Ecosystem And Urban Land Use Change In Port Harcourt Metropolis, Nigeria. - Earth Sciences Malaysia 2(1): 01-07.

[32] Wang, J. H. (2012): A Study on Air Pollutant Dispersion Surrounding High-level Residential Buildings in Natural Ventilation. - Chongqing University.

[33] Yang, L., Li, Y. (2011): Thermal conditions and ventilation in an ideal city model of Hong Kong. - Energy and Buildings 43(5): 1139-1148.

[34] Yuan, C., Ng, E., Norford, L. K. (2014): Improving air quality in high-density cities by understanding the relationship between air pollutant dispersion and urban morphologies. - Building and Environment 71: 245-258.

[35] Yuan, C., Ren, C., Ng, E. (2014): GIS-based surface roughness evaluation in the urban planning system to improve the wind environment-A study in Wuhan, China. - Urban Climate 10: 585-593.

[36] Zhang, X. Y., Jin, H. (2016): Optimization study on northeastern village forms based on the improvement of monsoon environment in winter. - Journal of Architecture (10): 8387.

[37] Zhang, Y. L., Zhao, M. X., Su, J. L., Lu, X., Lv, K. B. (2018): Novel model for cascading failure based on degree strength and its application in directed gene logic networks. Computational \& Mathematical Methods in Medicine, Article ID 8950794. DOI: $10.1155 / 2018 / 8950794$. 